\title{
Bolt Tightening Methods on the Combined Surface of Assembly Structure
}

\author{
L. W. Tseng ${ }^{1, *}$, C. H. Chung ${ }^{1}$, W. L. Huang ${ }^{2}$ \\ ${ }^{1}$ Department of Mechatronics Engineering, National Changhua University of Education, Taiwan \\ ${ }^{2}$ Precision Machinery Research \& Development Center, Taiwan
}

Received October 13, 2020; Revised December 15, 2020; Accepted December 28, 2020

\begin{abstract}
Cite This Paper in the following Citation Styles
(a): [1] L. W. Tseng, C. H. Chung, W. L. Huang, "Bolt Tightening Methods on the Combined Surface of Assembly Structure," Universal Journal of Mechanical Engineering, Vol. 8, No. 6, pp. 305 - 314, 2020. DOI: 10.13189/ujme.2020.080603.
\end{abstract}

(b): L. W. Tseng, C. H. Chung, W. L. Huang (2020). Bolt Tightening Methods on the Combined Surface of Assembly Structure. Universal Journal of Mechanical Engineering, 8(6), 305 - 314. DOI: 10.13189/ujme.2020.080603.

Copyright $\bigcirc 2020$ by authors, all rights reserved. Authors agree that this article remains permanently open access under the terms of the Creative Commons Attribution License 4.0 International License

\begin{abstract}
Machine tools are assembled by thousands of components. The surface between two components is the mating surface. The bolt tightening methods will affect the stress and deformation of mating surface which influences the accuracy and rigidity of machine tools. In the precision machinery industry, if the structure needs to tighten in line such as linear guideway, the senior engineers will tighten the bolts from sides to the middle or middle to sides instead of tightening in order. Furthermore, engineers use two-step of tightening rather than one-step of tightening. Based on their experience, these tightening methods will reduce the stress of mating surface and increase the rigidity of entire structure. In this study, the three bolts tightening model is used to investigate these tightening methods. Three bolts tightening CAD model is created by using the SolidWorks software. The finite element analysis is used the ANSYS workbench R19 software to simulate the bolt tightening methods (tightening sequences and pre-tightening force ratio) on the mating surface and entire model. From the simulation results, the minimum stress is observed in the tightening sequence from sides to middle and maximum stress is obtained in the tightening sequence in order. The experimental results of bolt tightening sequences match the simulation results. The stresses of mating surface and entire model drastically decrease when the tightening step is two-step of tightening. In two-step tightening process, the pre-tightening force ratio $1: 1$ is the optimal tightening methods for reducing the stress of mating surface compared to another pre-tightening force ratio.
\end{abstract}

Keywords Bolt Locking Methods, Tightening
Sequence, Machine Tools, Pre-Tightening Force Ratio, Mating Surface

\section{Introduction}

The machine tools are used to grind, cut, drill, shape, and squeeze the metal workpieces to mechanical elements or products which are required by different kinds of industries such as aerospace, biomedical engineering, automobile and green energy. The major components of machine tools are column structure, machine bed, spindle head, pad of anchor bolt and linear guideway. These major components are required to assemble together by bolts and nuts. During the assembly process, the bolts are used to tighten two components together. The contact surface between two components is defined as mating surface or combined surface. The stress and deformation of mating surface will influence the accuracy and rigidity of machine tools.

The bolt tightening methods such as tightening sequences, pre-tightening force ratio and tightening steps affect the stress and deformation of mating surface and entire assembly structure. Pawar et al. [1] used the ANSYS software to simulate the von-Mises stress, deformation and maximum principle stress on the single lap bolted joint. Based on their simulation results, the magnitude of pre-tightening force influenced the stress and deformation on the entire model and mating surface. The stress and deformation of mating surface and entire 
model increased with increasing the pre-tightening force values. Abid et al. [2] simulated the gasket bolted flange joint in different bolt tightening sequences and number of pass by using nonlinear finite element analysis. The contact stress or the stress on the mating surface variations along the circumference was observed from the finite element model. The maximum von-Mises stress was in the first tightening bolt and the minimum von-Mises stress was in the last two bolts. Fukuoka et al. [3] used the finite element methods to investigate bolt-tightening methods to achieve the uniform bolt preloads. Paolo et al. [4] proposed the concept of error compensation and designed a new measurement system able to measure the displacements in the mating surface of machine tools. Bouzid et al. [5] used a simple comprehensive analytical approach based on the interpolation technique to predict the gasket contact stress distribution in bolted joints. The methodology was very efficient when nonlinear modeling is involved. Liu et al [6] used the ABAQUS software to simulate the bolt tightening process on the mating surface. Sun et al. [7] proposed the mathematic equation to calculate the pre-tightening force of the bolt and used the ABAQUS software to simulate the stress and deformation on the single bolt tightening model. Fukuoka et al. [8] used the experimental and numerical methods to calculate bolt pre-tightening force based on the linear elastic material modelling. Nassar et al. $[9,10]$ proposed a new finite element model to investigate the bolt elastic interaction, tightening sequence and tightening force on the elastic interaction phenomenon. Wang et al. [11,12] used the numerical model and experimental model for calculating the interaction stiffness of two bolts tightening in joint member. Nechache et al. [13] proposed the finite element bolt tightening model to investigate creep effect of bolt tightening methods on the bolted joint. The pre-tightening force decreased in the high temperature and showed the creep-relaxation. The $70 \%$ of bolt load relaxation was obtained when the creep time was 10000 hours.

In machine tool, the finite element methods were used to calculate the stress, deformation and natural frequency. Kono et al. [14] used the stiffness model of horizontal milling machine to simulate the vibration in the machine tool. The lowest natural frequency was obtained with the proposed four supports design. The experiment results showed the natural frequency of horizontal milling machine decreased with four support model compared to three support models. Wang and Liu et al. [15] investigated the tightening sequences of anchor bolts for large computer numerical control (CNC) machine tools by using the simulation and experiments. Based on the simulation and experiment results, the deformation of machine bed was uniform when tightening sequence was from middle to sides. The large deformation was observed by tightening in order. Tseng et al. [16] used the finite element methods to simulate the effect of bolt locking methods on the mating surface of column structure and guideway in the machine tool. Based on their results, the minimum deformation was observed in the locking sequence from middle to both sides in the column structure. In the linear guideway structure, the minimum displacement of combined surface is obtained by using locking sequence from outside to the middle. The maximum displacement is obtained in locking sequence from right to the left order. In the anchor bolt design, increasing the radius of anchor bolt decreases the stress on the mating surface between the bolts and pads.

In the precision machinery industry, the senior engineers or experienced worker tighten the bolts to assemble the components of machine tool together. If the structure needs to tighten the bolts in line, they will tighten the bolts from sides to the middle or middle to sides instead of tightening in order. Moreover, engineers use two-step tightening the bolt instead of one-step tightening. Engineers use these methods (tightening sequences and steps) to reduce the stress and deformation of mating surface and improve the rigidity of machine tools based on their work experience. As a consequence, this study is used the three bolts tightening model to investigate effect of different tightening sequences and step on the stress and deformation of mating surface.

\section{Materials and Methods}

In this study, three bolt tightening model is created by using the SolidWorks software. The computer aid design (CAD) model is imported in ANSYS workbench 2019 R1 with the format IGES for finite element simulation. The finite element method is used the numerical mathematic technique to simulate or calculate the stress and deformation of the mating surface and entire structure in the three bolt tightening model. The finite element analysis procedure is listed in Figure 1.

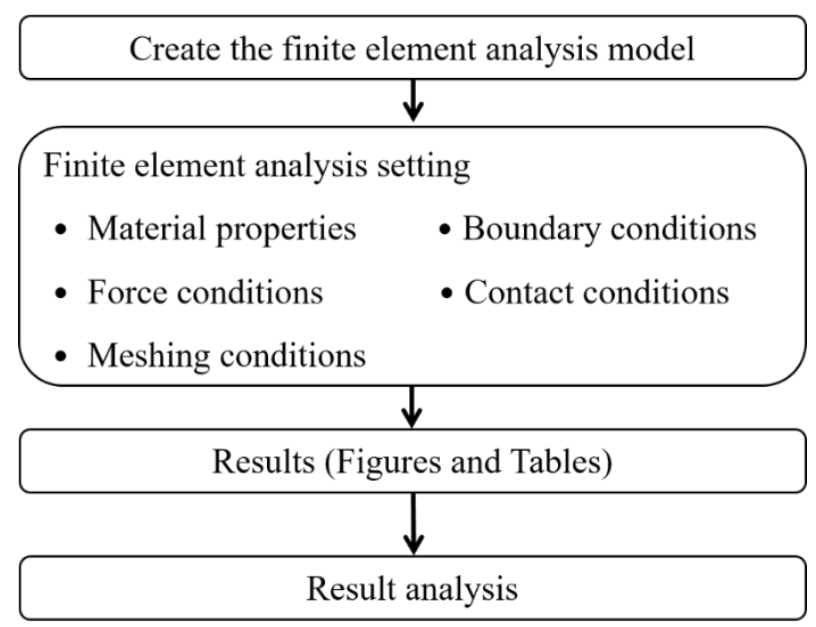

Figure 1. Finite element analysis procedure 


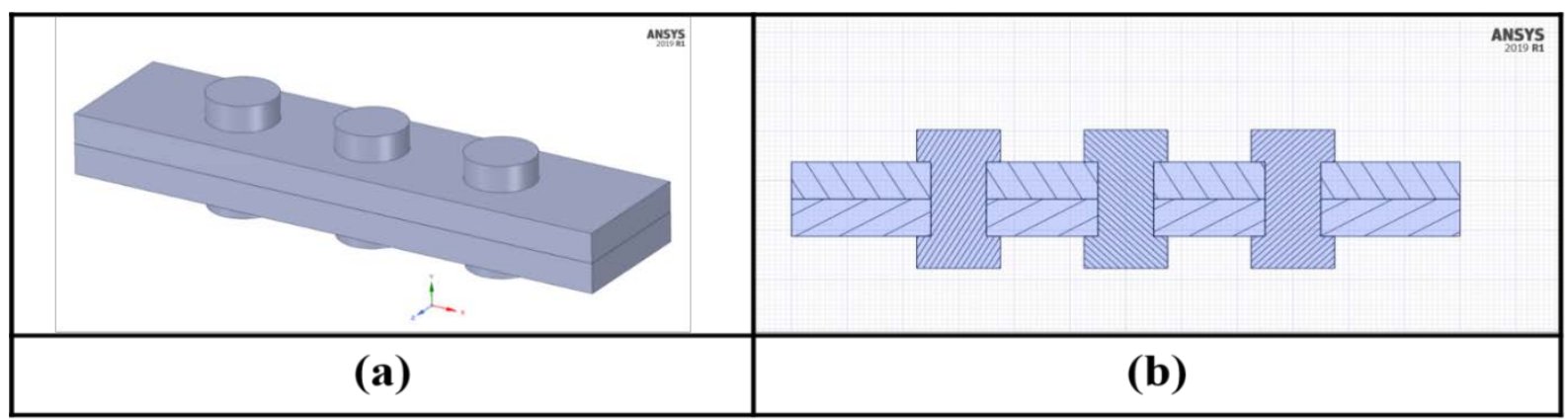

Figure 2. Three bolt tightening CAD model: (a) iso view and (b) perspective view.

\subsection{CAD Model of Machine Tool}

Figure 2(a) and (b) show the three bolt tightening CAD model after importing in ANSYS software. The top and bottom plates are the same dimension. The dimension of the plate is $240 \mathrm{~mm} \times 60 \mathrm{~mm} \times 15 \mathrm{~mm}$ (length $\times$ width $\times$ thickness). The bolt is used standard dimension with $\mathrm{M} 20 \times 30 \mathrm{~mm}$. The diameter of nut is $30 \mathrm{~mm}$ and the thickness is $13 \mathrm{~mm}$. The distance between two center holes is $60 \mathrm{~mm}$. In order to simplify the analysis process, one bolt and two nuts are assumed to one component or element. The screw thread is removed from the screw to avoid meshing problem.

\subsection{Material Properties}

In the three bolt tightening model, the material of top and bottom plates are selected the cast iron. The bolts and nuts are used alloy steel. The material properties of these two material are shown in Table 1.

Table 1. Material properties of cast iron and alloy steel

\begin{tabular}{|c|c|c|c|}
\hline Parts & Materials & E (GPa) & Poisson's ratio \\
\hline Top and bottom plates & cast iron & 120 & 0.25 \\
\hline Bolts and nuts & alloy steel & 210 & 0.3 \\
\hline
\end{tabular}

\subsection{Boundary Condition}

In three bolt tightening model, the four corners of mating surface between the top and bottom plates are selected fixed support, as shown in Figure 3. The fixed support represents the displacements in the $\mathrm{x}, \mathrm{y}$ and $\mathrm{z}$ direction is 0 .

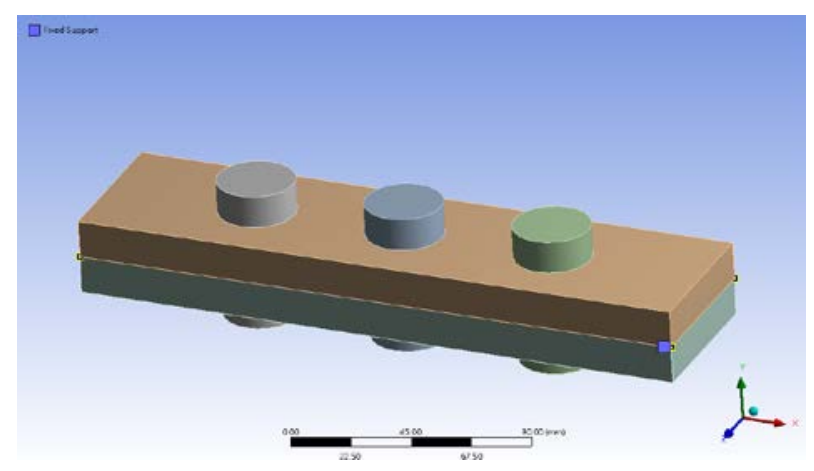

Figure 3. The boundary condition of three bolt tightening model.

\subsection{Force Condition}

\subsubsection{Calculation of pre-tightening force}

The pre-tightening force will generate during tightening the bolts. The equation for calculating the pre-tightening force is listed as follow $[7,15]$

$$
Q_{P}=\frac{T}{0.2 d}
$$

where Qp is the pre-tightening force $(\mathrm{N})$, $\mathrm{T}$ is the torque $(\mathrm{N}-\mathrm{m})$ and $\mathrm{d}$ is diameter of bolts $(\mathrm{mm})$.

In this study, diameter of bolt is $20 \mathrm{~mm}$ (M20) and torque are used to tight the bolts. The torque is $\mathrm{T}=160$ $\mathrm{N}-\mathrm{m}$. These two parameters plug into equation (1). The calculation of pre-tightening force is $40000 \mathrm{~N}$. Figure 4 displays the pre-tightening force setting of three bolts tightening model.

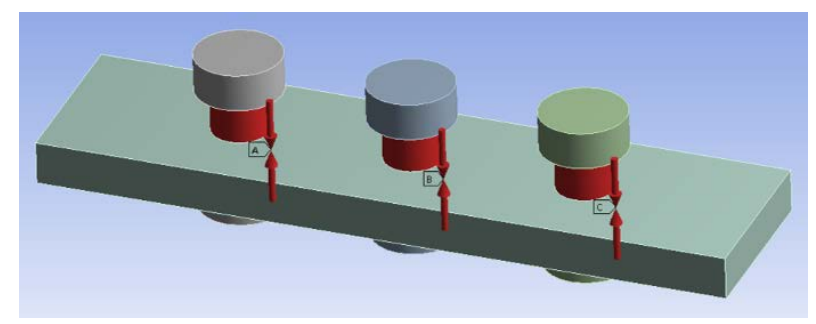

Figure 4. Pre-tightening force setting of three bolts tightening model.

\subsubsection{Tightening sequences setting}

In this study, the effect of tightening sequences on the stress and deformation of mating surface are investigated in three bolt tightening model. Figure 5 shows the side view of three bolt tightening model. In figure 5 , the numbers from 1 to 3 represent the bolt 1, bolt 2 and bolt 3 . The numbers are used to explain the bolt tightening sequence. For example, sequence 1 is first tightening the bolt 1 , next bolt 2 and next bolt 3 . Three different tightening sequences are listed in Table 2.

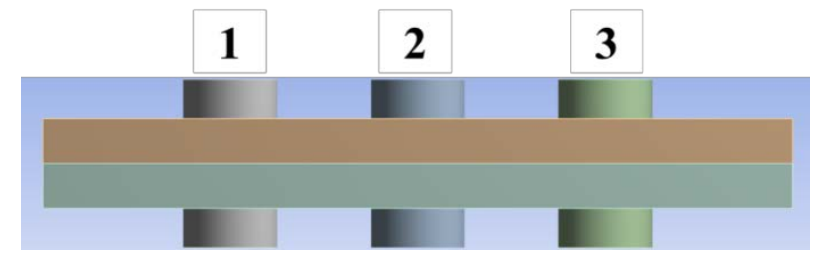

Figure 5. Side view of three bolt tightening model. The number is used to illustrate the bolt tightening sequence. 
Table 2. Tightening sequences of three bolt tightening model

\begin{tabular}{|c|c|c|}
\hline Sequence & $\begin{array}{c}\text { Pre-tightening } \\
\text { bolt number }\end{array}$ & Detail \\
\hline Sequence 1 & $1 \rightarrow 2 \rightarrow 3$ & Tighten in order \\
\hline Sequence 2 & $2 \rightarrow 1 \rightarrow 3$ & Tighten form middle to sides \\
\hline Sequence 3 & $1 \rightarrow 3 \rightarrow 2$ & Tighten from sides to middle \\
\hline
\end{tabular}

An example of tightening sequence 1 setting in ANSYS software is shown in Figure 6. In analysis setting, the number of steps is selected 3 and bolt pretension window will generate three steps. Sequence 1 is tightened in order from bolt 1 to bolt 3 . Bolt pretension window setting: step 1 is selected $40000 \mathrm{~N}$ and step 2 and 3 are chosen lock. Bolt pretension 2 window setting: step 1 and 3 are locked and step 2 is $40000 \mathrm{~N}$. Bolt pretension 3 window setting: step 1 and 2 are locked and step 3 is $40000 \mathrm{~N}$.

\subsubsection{Pre-tightening force ratio}

In two-step tightening process, the tightening formula is listed as follow:

$$
Q_{P}=Q_{P 1}+Q_{P 2}=a Q_{P}+b Q_{P}
$$

where: $\mathrm{Qp}$ is the pre-tightening force $(\mathrm{N})$ in one step tightening. The $\mathrm{Q}_{\mathrm{P} 1}$ and $\mathrm{Q}_{\mathrm{p} 2}$ are the pre-tightening force $(\mathrm{N})$ divided in two-step tightening process. $\mathrm{Q}_{\mathrm{P} 1}$ and $\mathrm{Q}_{\mathrm{P} 2}$ are the first and second steps of pre-tightening forces, respectively. $\mathrm{a}$ and $\mathrm{b}$ are the percent of the pre-tightening force.

The first and second pre-tightening force can be obtained by calculating the torque. In precision machinery industry, the tightening torque values can be controlled by digital torque wrench during assembling. For example, the torque value of tightening bolt is $160 \mathrm{~N}-\mathrm{m}$ and pre-tightening force is $40000 \mathrm{~N}$ in one-step tightening process based on the calculation of equation (1). If the pre-tightening force ratio is $a: b=2: 8$ which $a=20 \%$ and $\mathrm{b}=80 \%$ in two-step tightening process, the first toque is $\mathrm{T}_{1}=160(0.2)=32 \mathrm{~N}-\mathrm{m}$ and corresponding to pre-tightening force is $\mathrm{Q}_{\mathrm{P} 1}=(0.2) 40000=8000 \mathrm{~N}$. The second torque is $\mathrm{T}_{2}=160(0.8)=128 \mathrm{~N}-\mathrm{m}$ and corresponding to second pre-tightening force is $\mathrm{Q}_{\mathrm{P} 2}=(0.8) 40000=32000 \mathrm{~N}$. The different pre-tightening force ratio of this study is summarized in Table 3.

\section{Tightening Sequence 1}

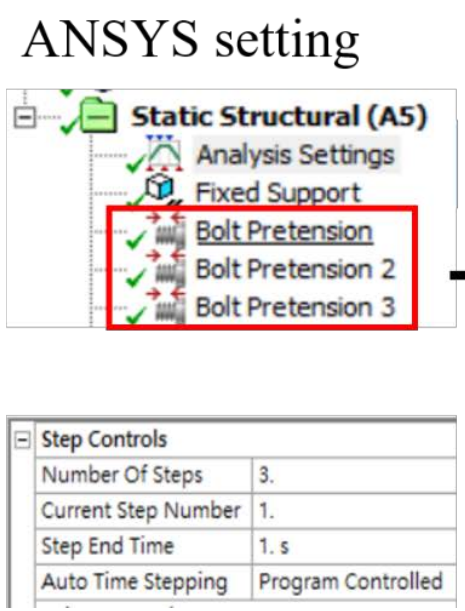

\section{Bolt Pretension}

\begin{tabular}{|l|l|l|l|l|l|l|l|}
\hline & Steps & $\sqrt{\checkmark}$ Define By & $\sqrt{\checkmark}$ Preload [N] & $\sqrt{\checkmark}$ Preadjustment [mm] & $\sqrt{ }$ & Increment [mm] \\
\hline 1 & 1. & Load & 40000 & N/A & N/A \\
\hline 2 & 2. & Lock & N/A & N/A & N/A \\
\hline 3 & 3. & Lock & N/A & N/A & N/A \\
\hline
\end{tabular}

\section{Bolt Pretension 2}

\begin{tabular}{|c|c|c|c|c|c|}
\hline & Steps & $\sqrt{\checkmark}$ Define By & $\sqrt{\checkmark}$ Preload [N] & $\sqrt{\checkmark}$ Preadjustment [mm] & $\sqrt{\sqrt{V}}$ Increment [mm] \\
\hline 1 & 1. & Open & N/A & N/A & N/A \\
\hline 2 & 2. & Load & 40000 & N/A & N/A \\
\hline 3 & 3. & Lock & N/A & N/A & N/A \\
\hline
\end{tabular}

\section{Bolt Pretension 3}

\begin{tabular}{|c|c|c|c|c|c|}
\hline & Steps & $\sqrt{ }$ Define By & $\sqrt{\checkmark}$ Preload [N] & $\sqrt{\checkmark}$ Preadjustment [mm] & $\sqrt{\checkmark}$ Increment [mm] \\
\hline 1 & 1. & Open & N/A & N/A & N/A \\
\hline 2 & 2. & Lock & N/A & N/A & N/A \\
\hline 3 & 3. & Load & 40000 & N/A & N/A \\
\hline
\end{tabular}

Figure 6. Tightening sequence 1 setting in ANSYS software

Table 3. Pre-tightening force ratio in two-step tightening process

\begin{tabular}{|c|c|c|c|c|c|c|c|c|c|}
\hline Number & 1 & 2 & 3 & 4 & 5 & 6 & 7 & 8 & 9 \\
\hline a & $90 \%$ & $80 \%$ & $70 \%$ & $60 \%$ & $50 \%$ & $40 \%$ & $30 \%$ & $20 \%$ & $10 \%$ \\
\hline b & $10 \%$ & $20 \%$ & $30 \%$ & $40 \%$ & $50 \%$ & $60 \%$ & $70 \%$ & $80 \%$ & $90 \%$ \\
\hline a:b & $9: 1$ & $8: 2$ & $7: 3$ & $6: 4$ & $5: 5$ & $4: 6$ & $3: 7$ & $2: 8$ & $1: 9$ \\
\hline
\end{tabular}




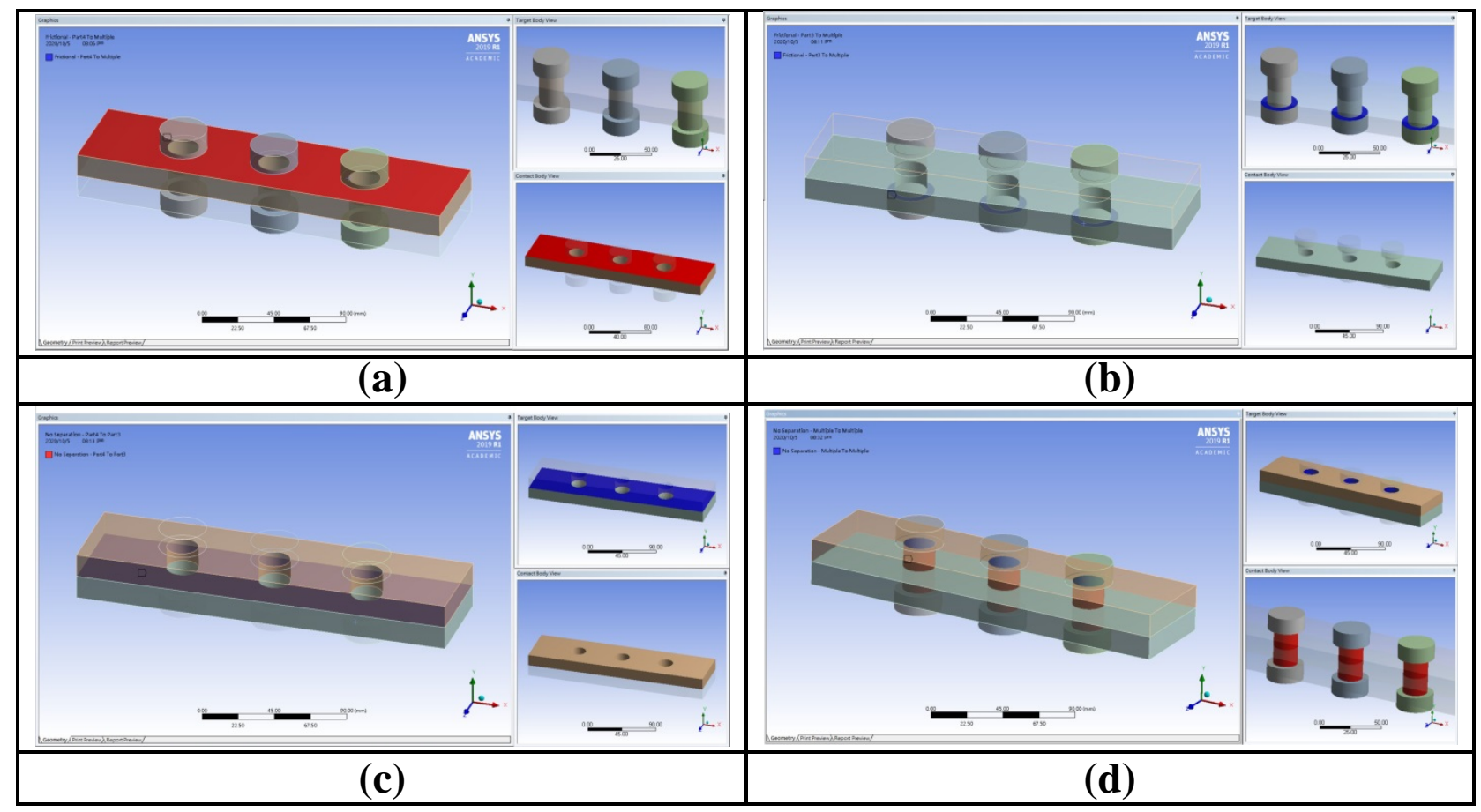

Figure 7. Contact conditions of three bolt tightening model: (a) the contact surface between top plate and nuts, (b) the contact surface between bottom plate and nuts, (c) the contact surface between top and bottom plates and (d) the contact surface between the three bolts and three holes.

\subsection{Contact Condition}

There are total four contact regions in three bolt tightening model. (a) The contact surface between top plate and bottom of nuts, (b) the contact surface between bottom plate and bottom of nuts, (c) the contact surface between top and bottom plates and (d) the contact surfaces between the bolts and holes. The contact conditions for (a), (b) and (d) are selected no separation. The contact condition for (c) is chosen friction. The coefficient of friction is 0.18 . The contact conditions are shown in the Figure 7(a), (b), (c), (d) and Table 4.

Table 4. Contact condition of three bolt tightening model

\begin{tabular}{|c|c|}
\hline Contact surface & Conditions \\
\hline Bolt nuts and top plate & No separation \\
\hline Bolt nuts and bottom plate & No separation \\
\hline Top and bottom plates & Frictional $(\mu \mathrm{s}=0.18)$ \\
\hline Bolts and holes & No separation \\
\hline
\end{tabular}

\subsection{Meshing Condition}

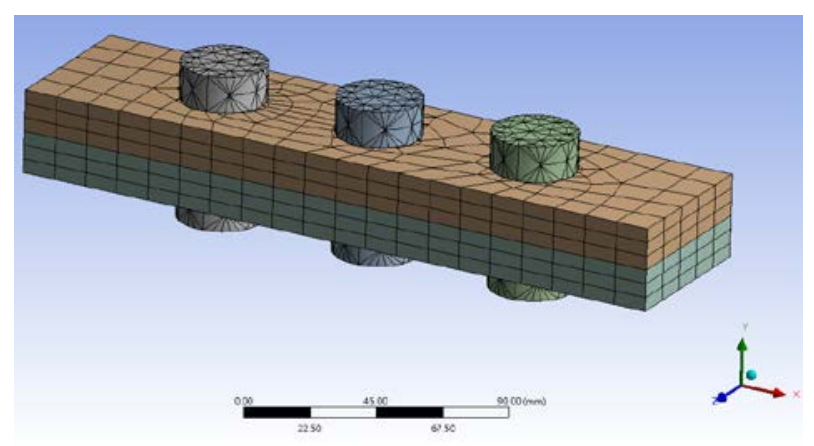

Figure 8. Meshing condition of three bolt tightening model
The meshing condition of three bolt tightening model is used the fine meshing. The number of elements is 4056 and the number of nodes is 13499. The model after meshing is shown in Figure 8.

\subsection{Experimental Setup}

The experimental tests are used to verify the simulation analysis results of tightening sequences. Figure 9(a) shows the experimental setup of the bolt tightening before assembling two components together. The dimension of each top and bottom plate is $577.5 \mathrm{~mm} \times 80 \mathrm{~mm} \times 50 \mathrm{~mm}$ (length $\times$ width $\times$ thickness). The dimension of bolt is M12. The experimental procedure is listed as follow:

First, the Fujifilm Prescale is put on the upper surface of bottom plate. The film (Fujifilm Prescale) is used to measure the stress or pressure of the mating surface in the machine tool. The color of film is white without applying any force on the film. When the stress is applied on the film, the red patches (color) will appear on the film. The color density changes according to the various stress levels.

Second, the top plate is placed in parallel above the bottom plate. Top and bottom plates are fixed by fixture to avoid moving during bolt tightening.

Third, the bolts tighten in different sequences, as shown in Figure 9(b). The torques of tightening are selected 40 $\mathrm{N}-\mathrm{m}$ and $80 \mathrm{~N}-\mathrm{m}$, which can be controlled by torque wrench. The tightening sequences are sequence 1 (tight in order), maximum stress case and sequence 3 (tight from sides to middle), minimum stress case.

Fourth, the top and bottom plates are combined together 
after tightening. Figure 9(c) displays the combination of two components.

Fifth, we unscrew the bolts and then remove the top plate. Figure 9(d) shows the bottom plate and film after removing the bolts and top plate.

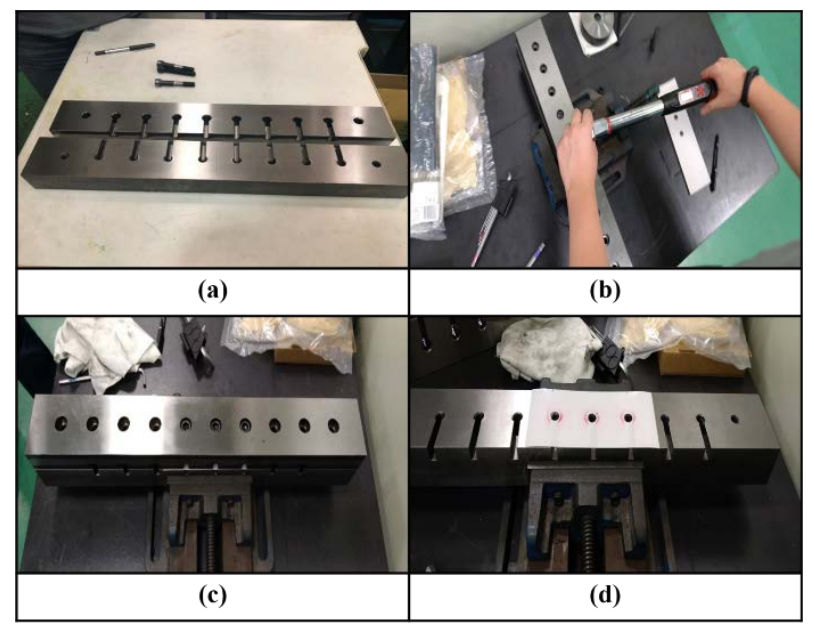

Figure 9. (a) Top and bottom plates before tightening, (b) tight the bolts by torque wrench, (c) the top and bottom plates after tightening and (d) the bottom plate after removing the top plate.

\section{Results and Discussion}

\subsection{The Effect of Tightening Sequences on Three Bolt Tightening Model}

\subsection{1. von-Mises stress on the entire model}

Figure 10(a), (b) and (c) show the von-Mises stress of three bolt tightening model in three different tightening sequences. The maximum von-Mises stresses of three tightening sequences are summarized in Figure 10(d). From the comparison results, the minimum stress and the maximum stress are obtained in the sequence 3 (tight from sides to middle) and the sequence 1 (tight in order), respectively.

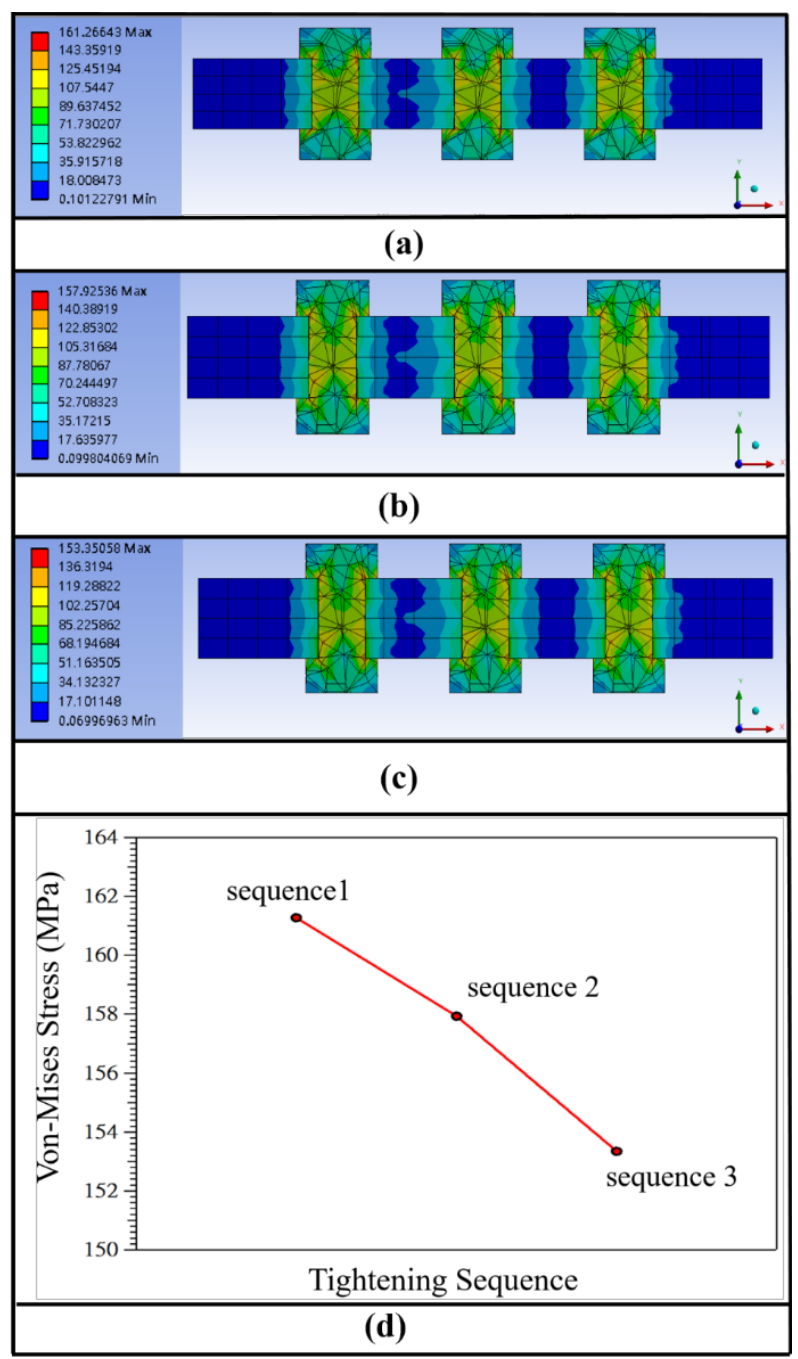

Figure 10. The von-Mises stress of three bolt tightening model in three different tightening sequences: (a) sequence 1, (b) sequence 2 and (c) sequence 3. (d) Comparison of von Mises stress in three tightening sequences 


\subsection{2. von-Mises stress on the mating surface}

Figure 11(a), (b) and (c) show the von-Mises stress on the mating surface in three different tightening sequences. The maximum von-Mises stresses of sequence 1 , sequence 2 and sequence 3 are $62.49 \mathrm{MPa}, 61.31 \mathrm{MPa}$ and 61.12 MPa, respectively. The maximum von-Mises stresses for three tightening sequences are summarized in Figure 11(d). From the comparison result, the minimum stress is obtained in the sequence 3 (sides to middle) and the maximum von-Mises stress is observed in sequence 1 (in order).

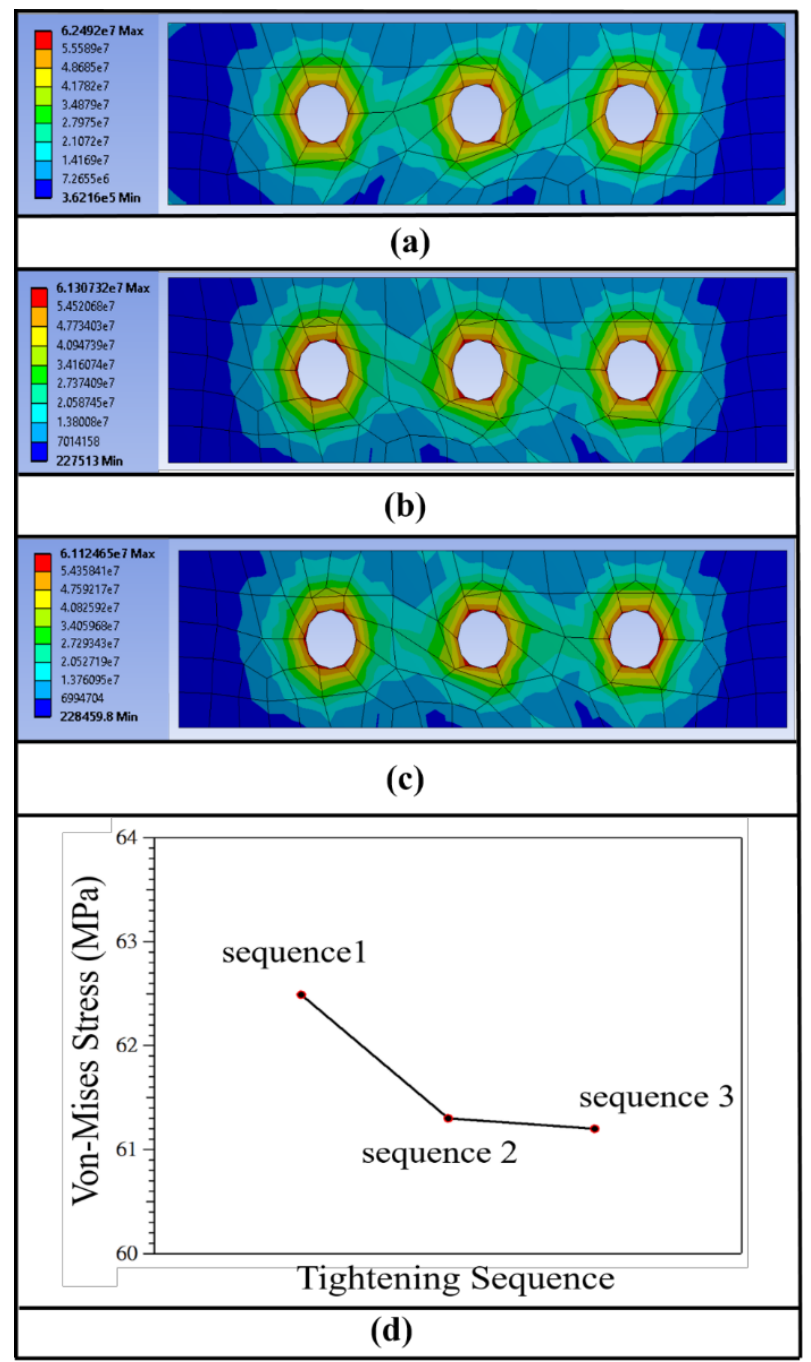

Figure 11. The von-Mises stress of mating surface in three different tightening sequence. (a) sequence 1, (b) sequence 2 and (c) sequence 3. (d) Comparison of von Mises stress in three tightening sequences.

\subsubsection{Total deformation on mating surface}

Figure 12(a), (b) and (c) show the total deformation of the mating surface in three different tightening sequences. The maximum deformation in sequence 1 , sequence 2 and sequence 3 are $0.015154 \mathrm{~mm}, 0.01507 \mathrm{~mm}$ and 0.0088659 $\mathrm{mm}$, respectively. The maximum deformations of three tightening sequences are summarized in Figure 12(d).
From the comparison result, the minimum deformation $(\mu \mathrm{m})$ of mating surface is obtained in the tightening sequence from sides to middle and the maximum deformation $(\mu \mathrm{m})$ of mating surface is found in the tightening sequence in order.

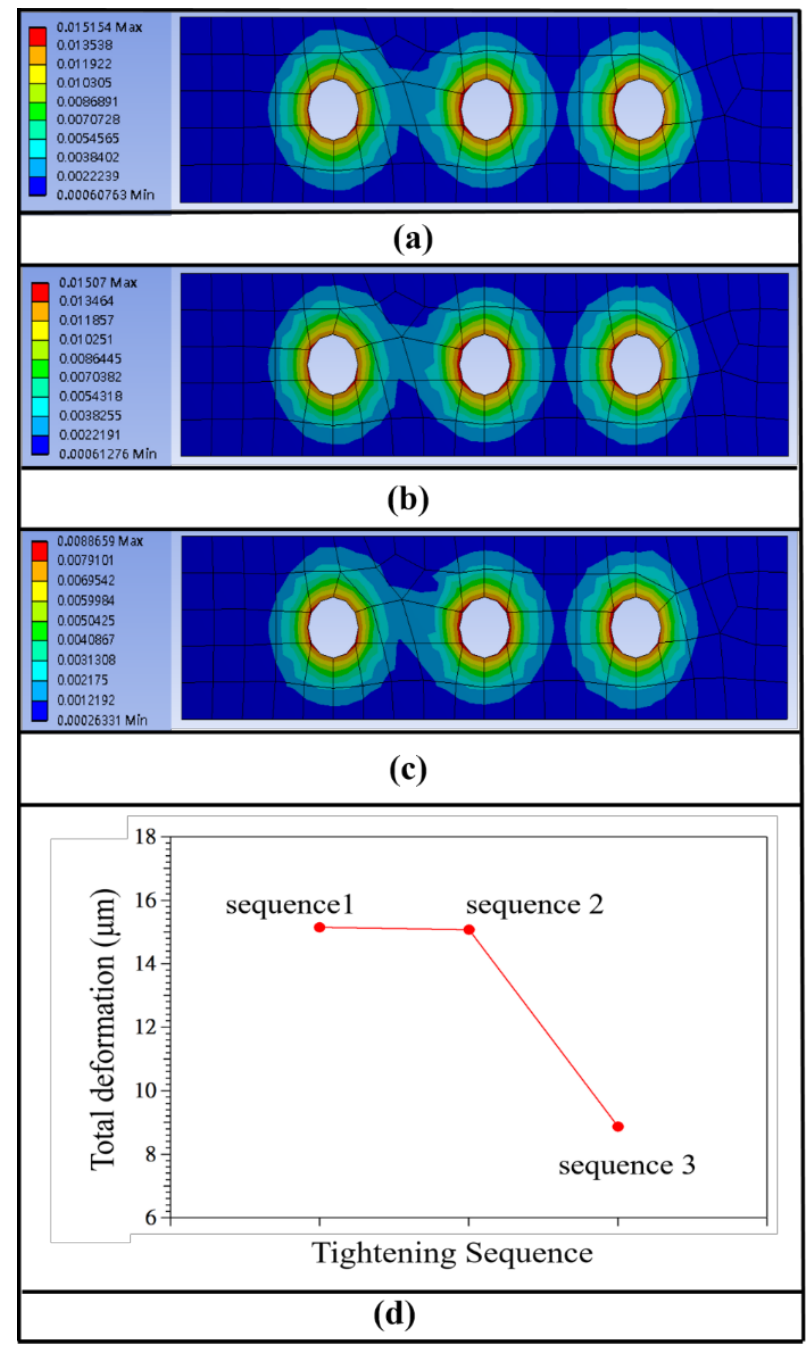

Figure 12. Total deformation of mating surface in three different tightening sequence. (a) sequence 1, (b) sequence 2 and (c) sequence 3. (d) Comparison of total deformation in three tightening sequences.

\subsection{The Effect of Pre-Tightening Force Ratio on Three Bolt Tightening Model}

3.2.1. von-Mises stress on entire model and mating surface in sequence 1

Figure 13(a) shows different steps of pre-tightening force ratio on the three bolts tightening model. The tightening sequence is sequence 1 . From the results, when the tightening step changes from 1 to 2 , the stress decreases in all pre-tightening force ratio. The minimum stress is in pre-tightening force ratio 1:1, as shown inside the Figure 13(a). Figure 13 (b) shows one-step and two-step with the different pre-tightening force ratio on 
the mating surface in the sequence 1. From the results, all the stress values in two-step with different pre-tightening ratio are drastically decreased compared to one-step tightening. The minimum stress is in pre-tightening force ratio 1:1, as shown inside the Figure 13(b). The stress values of entire model and mating surface in sequence 1 with different pre-tightening ratio are summarized in Table 5.

Table 5. The stress values of entire model and mating surface with different pre-tightening force ratio in two-step tightening condition

\begin{tabular}{|c|c|c|}
\hline Pre-tightening force ratio & von-Mises stress of entire model (MPa) & von-Mises stress of mating surface (MPa) \\
\hline $100 \%$ & 161.270 & 62.49 \\
\hline $9: 1$ & 161.082 & 59.488525 \\
\hline $8: 2$ & 161.103 & 59.488512 \\
\hline $7: 3$ & 161.122 & 59.488512 \\
\hline $6: 4$ & 161.143 & 59.488535 \\
\hline $5: 5=1: 1$ & 161.062 & 59.451 \\
\hline $4: 6$ & 161.183 & 59.488512 \\
\hline $3: 7$ & 161.204 & 59.4885 \\
\hline $2: 8$ & 161.224 & 59.489 \\
\hline $1: 9$ & 161.240 & 59.488501 \\
\hline
\end{tabular}

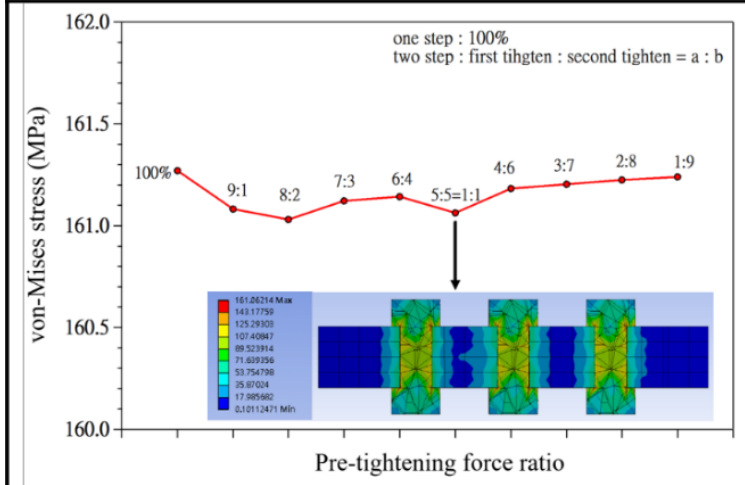

(a)

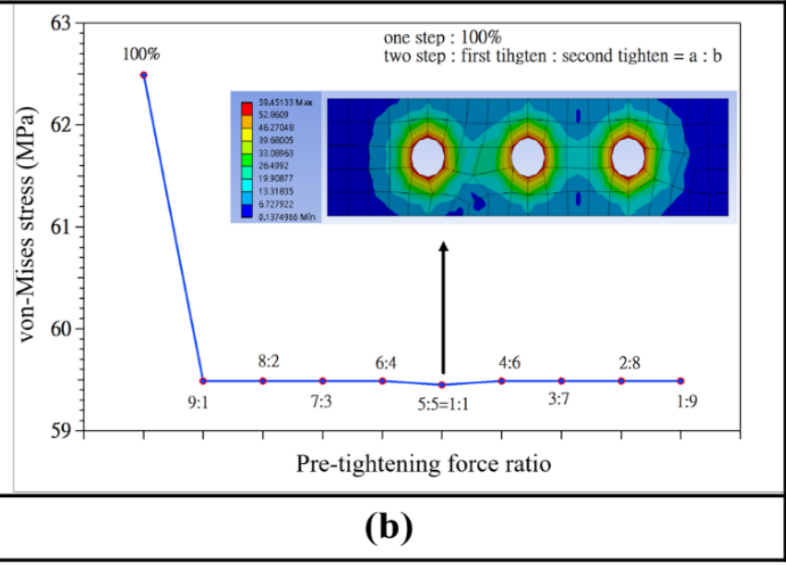

Figure 13. The von-Mises stress in sequence 1 with different pre-tightening force ratio in (a) three bolt tightening model and (b) mating surface. Inside the Figure is the stresses of entire model and mating surface with pretension force ratio 1:1.

Table 6. Comparison results of three tightening sequences with pre-tightening force ratio 1:1.

\begin{tabular}{|c|c|c|c|c|}
\hline \multirow{2}{*}{ Sequence } & \multicolumn{2}{|c|}{ One-step tightening } & \multicolumn{2}{c|}{$\begin{array}{c}\text { Two-step tightening } \\
\text { (pre-tightening force ratio 1:1) }\end{array}$} \\
\cline { 2 - 5 } & \multicolumn{2}{|c|}{ von-Mises stress (MPa) } & \multicolumn{2}{|c|}{ von-Mises stress (MPa) } \\
\cline { 2 - 5 } & entire model & mating surface & entire model & mating surface \\
\hline Sequence 1 & 161.270 & 62.49 & 161.062 & 59.451 \\
\hline Sequence 2 & 157.93 & 61.31 & 141.96 & 59.00 \\
\hline Sequence 3 & 153.35 & 61.12 & 138.01 & 57.43 \\
\hline
\end{tabular}




\subsubsection{Pre-tightening force ratio on sequence 2 and sequence 3}

From above results of sequence 1 in different pre-tightening force ratio, the minimum stress values of entire model and mating surface are obtained in the pre-tightening force ratio 1:1. The same pre-tightening ratio is applied in sequence 2 and sequence 3. Figure 14 (a) and (b) show the von-Mises stress of the entire model and mating surface in sequence 2. Figure 14 (c) and (d) show the von-Mises stress of the entire model and mating surface in sequence 3. From the results, the stresses of entire model and mating surface in both sequence 2 and sequence 3 in the two-step pre-tightening force ratio 1:1 are smaller than that in sequence 1 with one-step tightening. The comparison results of different tightening sequences, tightening steps and pre-tightening force ratio are summarized in Table 6 .

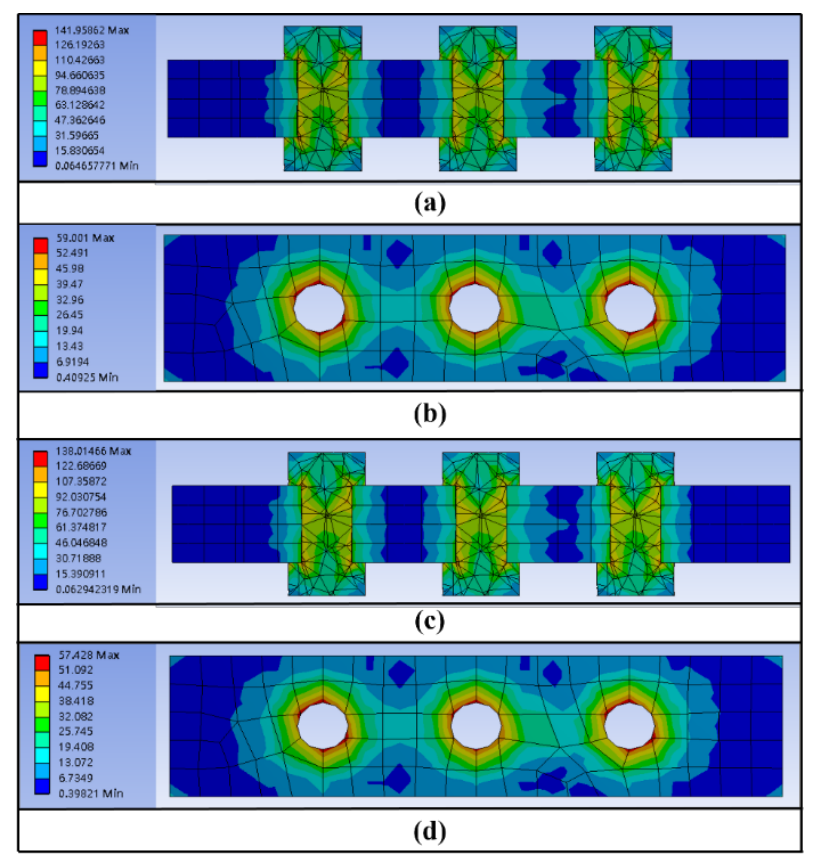

Figure 14. The von-Mises stress on (a) entire model in sequence 2, (b) mating surface in sequence 2, (c) entire model in sequence 3 and (d) mating surface in sequence 3 .

\subsection{Experimental Results of Bolt Tightening Sequences}

Figure 15(a) and (b) show the experimental results of film 1 (tighten in order) and film 2 (tighten from outside to middle) under the torque $40 \mathrm{~N}$-m. From the results, the red patches (color) appear on the both films after the test. The red color density of holes in film 1 is deeper than that in film 2. In addition, the patches' surface area between two holes of the film 1 is larger than that of the film 2 . The results indicate the stress values of film 1 are larger than that of film 2. If the torque value changes to $80 \mathrm{~N}-\mathrm{m}$, the difference color density distribution between these two tightening sequences is more obvious. The red patches' area of film 3 is deeper and larger than that of film 4, as shown in Figure 15(c) and (d). From comparison, the results indicate the stress values of tighten in order are larger than that of tighten from side to middle. The experimental results agree with the simulation results.

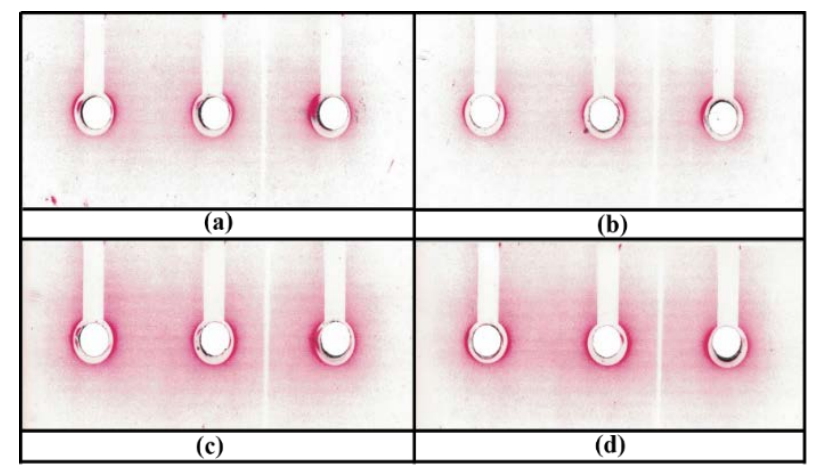

Figure 15. The experimental results of films with different tightening sequences. Under torque $40 \mathrm{~N}$-m: (a) film 1 tighten in order and (b) film 2 tighten from outside to middle. Under torque $80 \mathrm{~N}$-m: (c) film 3 tighten in order and (d) film 4 tighten from outside to middle.

\section{Conclusions}

In summary, the effect of bolts locking sequences and pre-tightening force ratio on the stress and deformation of mating surface in three bolt tightening model was investigated for the first time by using the finite element analysis. Major findings can be summarized as follows:

(a) From the tightening sequence results, the minimum stress is obtained in the sequence 3 (tight from sides to middle) and the maximum stress is observed in the sequence 1 (tight in order).

(b) From the one-step and two-step tightening results, when the tightening step changes from one-step to two-step, the stress and deformation values of the mating surface and entire three bolt tightening model drastically decrease their values in all three tightening sequences.

(c) From the different pre-tightening force ratio of two-step tightening process results, the minimum von-Mises stress is obtained in the ratio of first tightening to second tightening force is 1 to 1 .

The optimal tightening methods for bolt tightening in line structure are (1) sequence: tighten form sides to middle, (2) step: tighten in two-step and (3) pre-tightening force ratio: first and second tightening ratio is 1:1.

(e) The experimental results show the red color density and area of film tighten in order is deeper and larger than that of film tighten from sides to middle. The results indicate the stress level of tighten in order is larger than that of tighten from sides to middle. The experimental results of tightening sequences match the simulation results. 


\section{Acknowledgements}

The authors gratefully acknowledge that Precision Machinery Research \& Development Center supported for this work. Project number is 108TR04. Finite element simulation and technical experience of machine tools from Dr. Wei-Lun Huang are gratefully acknowledged. Thanks graduate student C.H. Chung for all the experimental tests. Thanks CADMEN Taiwan Auto-Design Co. (TADC) technical help for the ANSYS software setting in bolt tightening.

\section{REFERENCES}

[1] Pawar J.S., Chouksey M., K. Tripathi, "Modeling and Stress Analysis of Single Lap Bolted Joint," Universal Journal of Mechanical Engineering, vol. 3, no.1, pp. 21-26, 2015.

[2] Abid M., S. Hussain, "Relaxation Behaviour of Gasketed Joints During Assembly Using Finite Element Analysis," Sadhana, vol. 35, pp. 31-43, 2010.

[3] Fukuoka T., T. Takaki, "Finite Element Simulation of Bolt-Up Process of Pipe Flange Connections," Journal Pressure Vessel Technology, vol. 23, pp. 282-287, 2001.

[4] Bosetti P., S. Bruschi, "Enhancing Positioning Accuracy of CNC Machine Tools by Means of Direct Measurement of Deformation," International Journal Advanced Manufacture Technology, vol. 58, pp. 651-662, 2012.

[5] Bouzid A., H. Champliaud, "Contact Stress Evaluation of Non-Linear Gaskets Using Dual Kriging Interpolation," Journal Pressure Vessel Technology, vol. 126, pp. 445-450, 2004.

[6] Liu K., W. Liu. "Analysis of Bolt Preload Based on ABAQUS," Machinery Manufacturing and Automation, vol. 2, pp. 105-107, 2011.
[7] Sun X.M., Y.F. Mai. "Analysis of Stress under Bolt Pretension, An improved Stiffness Model for Bolted Joints," Electronic Science and Technique, vol. 2, pp. 65-67, 2017.

[8] Fukuoka T., T. Takaki. "Finite Element Simulation of Bolt-Up Process of Pipe Flange Connections with Spiral Wound Gasket," Journal Pressure Vessel Technology, vol. 125, pp. 371-377, 2003.

[9] Nassar S.A., X. Yang. "Novel Formulation of Bolt Elastic Interaction in Gasketed Joints," International Journal Pressure Vessel Technology, vol. 05, pp. 131-135, 2009.

[10] Nassar S.A., A. Abboud. "An Improved Stiffness Model for Bolted Joints," Journal of Mechanical Design, vol. 131, pp. 25-29, 2009.

[11] Wang Y.Q., Wu J.K., H.B. Liu. "Modeling and Numerical Analysis of Multi-Bolt Elastic Interaction with Bolt Stress Relaxation," Journal of Mechanical Engineering Science, vol. 230, pp. 2579-2582, 2016.

[12] Wang Y., Wu J.K., Liu H., Kuang K., Cui X.W., L.S. Han. "Analysis of Elastic Interaction Stiffness and Its Effect on Bolt Preloading," International Journal of Mechanical Sciences, vol. 130, pp. 307-314, 2017.

[13] Nechache A., A.H. Bouzid. "Creep Analysis of Bolted Flange Joints," International Journal of Pressure Vessels and Piping, vol. 84, pp. 185-194, 2007.

[14] Kono D. , Nishio S., Yamaji I., A. Matsubara, "A Method for Stiffness Tuning of Machine Tool Supports Considering Contact Stiffness," International Journal of Machine Tools \& Manufacture, vol. 90, pp. 50-59, 2015.

[15] Liu H., Wu J., Liu K., Kung K., Liu Q., Liu Z., Y. Wang, "Pretightening Sequence Planning of Anchor Bolts Based on Structure Uniform Deformation for Large CNC Machine Tools," International Journal of Machine Tools and Manufacture, vol. 136, pp. 1-18, 2019.

[16] Tseng L.W., Wu C.Y., Tsai H.Y., Chung C.H., W.L. Huang, "The Effect of Bolt Locking Sequences and Anchor Bolt Design on Machine Tool," Universal Journal of Mechanical Engineering, vol. 8, no. 5, pp. 3310-3322, 2020. 